\title{
PETRÓLEO E EMPREGO: UMA ANÁLISE EM MUNICÍPIOS SELECIONADOS DO ESTADO DO RIO DE JANEIRO
}

\author{
OIL AND JOBS: AN ANALYSIS OF SELECTED MUNICIPALITIES IN THE STATE OF RIO DE JANEIRO
}

\section{RESUMO}

A descoberta e exploração de petróleo nos reservatórios na camada do pré-sal ocasionou o deslocamento de investimentos da Bacia de Campos para a Bacia de Santos, e, consequentemente, provocou alterações no mercado de trabalho das regiões produtoras. Deste modo, o objetivo do presente texto é analisar o impacto do setor de petróleo no mercado de trabalho nos locais em que são desenvolvidas as atividades de Exploração e Produção (E\&P), por meio da análise de um número equivalente de municípios confrontantes a ambas as bacias, durante o período compreendido entre os anos de 2000 até o presente. Foram consideradas informações referentes à população residente, aos postos de trabalho e ao nível educacional. $\mathrm{O}$ estudo indica que os municípios que abrigam equipamentos da indústria propriamente dita são os que apresentam os melhores indicadores quanto ao emprego e ao nível educacional. $O$ estudo é concluído ressaltando que as transformações estruturais da geopolítica do petróleo tornam os prognósticos sobre a evolução do setor um terreno altamente movediço, embora sejam necessárias análises sobre cenários futuros.

Palavras-chave: Petróleo. Bacia de Campos. Bacia de Santos. Pré-sal. Emprego.

\section{ABSTRACT}

Discovering and exploring oil in the pre-salt layer reservoirs displaced investments from the Campos Basin to the Santos Basin, causing changes in the labor market in the oil-producing regions. Hence, the present study seeks to analyze the impact of the oil sector on the labor market in places where Exploration and Production (E\&P) activities are carried out, by means of the analysis of an equal number of municipalities bordering both basins, from the 2000 s to the present. Information related to resident population, jobs, and educational level was considered. According to this study, municipalities that house equipment from this industry are those that provide the best indices in terms of jobs and educational level. In conclusion, the study stresses that structural changes in oil geopolitics make estimates of the evolution of the sector a very uncertain topic; however, analyses of future scenarios are still necessary.

Keywords: Oil. Campos Basin. Santos Basin. Pre-salt. Jobs.

\author{
Rosélia Piquet ${ }^{a}$ \\ iD Marlúcia Junger Lumbreras a, b \\ iD Richard de Castro ${ }^{a}$ \\ a Universidade Candido Mendes (UCAM), \\ Campos dos Goytacazes, RJ, Brasil

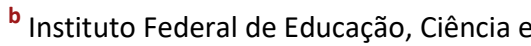 \\ Tecnologia Fluminense (IFF), Campos dos \\ Goytacazes, RJ, Brasil
}

DOI: 10.12957/geouerj.2020.48417

Correpondência: ropiquet@terra.com.br

Recebido em: 18 set. 2019 Revisado em: 16 out. 2019 Aceito em: $19 \mathrm{dez} .2019$ 


\section{INTRODUÇÃO}

A crise política e econômica de âmbito nacional, com queda dos níveis de produção e emprego que atinge o país desde 2014, assume caráter mais profundo no Estado do Rio de Janeiro e em seus municípios, visto que, aos impactos negativos que alcançam todos os entes da federação, somam-se os decorrentes das oscilações dos preços internacionais do petróleo, das turbulências internas atravessadas pelo setor.

Dentre as mudanças, cabe destaque o deslocamento da produção entre as Bacias de Campos e de Santos, em função da descoberta e exploração dos reservatórios na camada do pré-sal. Tal descoberta canalizou os investimentos em exploração e produção para as promissoras áreas do pré-sal em razão de sua elevada produtividade. Como as reservas encontram-se predominantemente localizadas na Bacia de Santos, na plataforma continental confrontante aos estados de São Paulo e Rio de Janeiro, os investimentos ao deslocarem-se dos campos maduros da Bacia de Campos (localizada na plataforma continental confrontante ao Rio de Janeiro e ao Espírito Santo) para a nova e promissora área, afetam negativamente os municípios do norte fluminense, beneficiando municípios da região metropolitana e ao sul do estado.

O objetivo do presente texto é analisar como um setor de atividade altamente internacionalizado característica básica do setor de petróleo - impacta o mercado de trabalho nos locais em que são desenvolvidas as atividades de Exploração e Produção (E\&P) de petróleo e gás. Parte-se da premissa que as pesquisas que buscam melhor compreender os efeitos da indústria petrolífera no desenvolvimento econômico em âmbito local poderão subsidiar políticas públicas voltadas à promoção de seus efeitos em âmbito regional e nacional.

O texto, além desta Introdução e das Conclusões, no primeiro item apresenta os critérios de seleção dos municípios, o período em que se desenvolve a análise e as fontes de dados utilizadas. O segundo item apresenta uma breve síntese do perfil dos municípios selecionados. O terceiro mostra, ainda que de forma sintética, os diferentes momentos históricos em que as atividades de E\&P offshore têm início em ambas as bacias. A seguir, no quarto item, são apresentados os dados levantados sobre o processo das mudanças ocorridas, segundo os indicadores selecionados. O quinto item contem uma análise das perspectivas do setor petrolífero no Estado do Rio de Janeiro. Nas Conclusões serão discutidas questões referentes às perspectivas do setor petrolífero no Brasil, uma vez que além da relevância para o desenvolvimento local e regional, o petróleo é um produto estratégico para a segurança energética de qualquer país e, portanto, a defesa dos efeitos positivos que gera é de interesse em âmbito nacional. 
As atividades petrolíferas ao mesmo tempo em que se desenvolvem de forma quase isolada nas localidades onde se processam a exploração e produção de petróleo e gás, por tratar-se de setor produtivo de alta tecnologia mais conectado ao mercado internacional, simultaneamente funciona como motor propulsor de riqueza de duas naturezas: por meio da multiplicação de empresas e empregos diretamente vinculados ao setor, assim como pelos pagamentos de elevadas somas sob a forma de royalties e participações especiais a um conjunto de municípios. Essas rendas muitas vezes têm papel mais significativo nas receitas orçamentárias de certos municípios do que as atividades diretamente relacionadas à indústria, em decorrência da lógica geográfica que preside a legislação brasileira sobre as regras de rateio quanto aos royalties e as participações especiais. $^{1}$

Por esse motivo, ocorre que um conjunto especial de municípios passa a receber parcelas significativas das rendas públicas do setor, apenas por estarem próximos às áreas de produção marítima, embora possuindo frágeis relações com a atividade petrolífera. Esses municípios, embora de modo equivocado, passam a ser designados pela expressão "município produtor". O recebimento de tais rendas influencia fortemente a dinâmica municipal sendo, contudo, altamente instáveis, dado que flutuam em função dos preços do petróleo no mercado internacional. Deste modo, os municípios serão selecionados dentre os dez maiores recebedores no Estado do Rio de Janeiro, conforme apresentado na tabela a seguir.

Tabela 1. Dez maiores recebedores de Royalties e Participações Especiais - Estado do Rio de Janeiro, no ano de 2018, em valores correntes. Fonte: Boletim Info Royalties, Universidade Candido Mendes - Campos, 22/06/2019

\begin{tabular}{lccc}
\hline \multicolumn{1}{c}{ Beneficiário } & Royalties (R\$) & Part. Especiais (R\$) & Royalties + PE (R\$) \\
\hline Maricá & $518.355 .214,02$ & $996.040 .580,90$ & $1.514 .395 .794,92$ \\
Niterói & $456.258 .702,10$ & $876.840 .399,60$ & $1.333 .099 .101,70$ \\
C. dos Goytacazes & $458.355 .956,28$ & $216.724 .914,96$ & $675.080 .871,24$ \\
Macaé & $585.385 .868,09$ & $16.650 .867,98$ & $602.036 .736,07$ \\
Rio de Janeiro & $173.465 .111,77$ & $163.299 .062,82$ & $336.764 .174,59$ \\
Rio das Ostras & $153.215 .437,89$ & $41.614 .803,58$ & $194.830 .241,47$ \\
Cabo Frio & $151.760 .460,20$ & $41.070 .748,81$ & $192.831 .209,01$ \\
São João da Barra & $114.652 .978,26$ & $48.626 .843,98$ & $163.279 .822,24$ \\
Angra dos Reis & $124.740 .946,84$ & 0,00 & $124.740 .946,84$ \\
Paraty & $114.535 .530,15$ & $5.968 .895,04$ & $120.504 .425,19$ \\
\hline
\end{tabular}

Como o objetivo do artigo é destacar as mudanças ocorridas em função das descobertas de petróleo e gás nos campos do pré-sal, selecionou-se número equivalente de municípios confrontantes à Bacia de Campos,

\footnotetext{
${ }^{1}$ Fazem jus ao recebimento de royalties e participações especiais os municípios confrontantes com campos produtores de petróleo de acordo com as linhas geodésicas ortogonais e paralelas desenhadas pelo IBGE e usadas como referências nas cartas náuticas, conforme estabelecido pela Lei 7.525/1986.
} 
que se estende de Vitória até Arraial do Cabo com área de $100 \mathrm{mil} \mathrm{km²}$, e à Bacia de Santos, a maior bacia sedimentar offshore do país, com área total de $350 \mathrm{mil} \mathrm{km}^{2}$, que se estende de Cabo Frio, RJ até Florianópolis, SC.

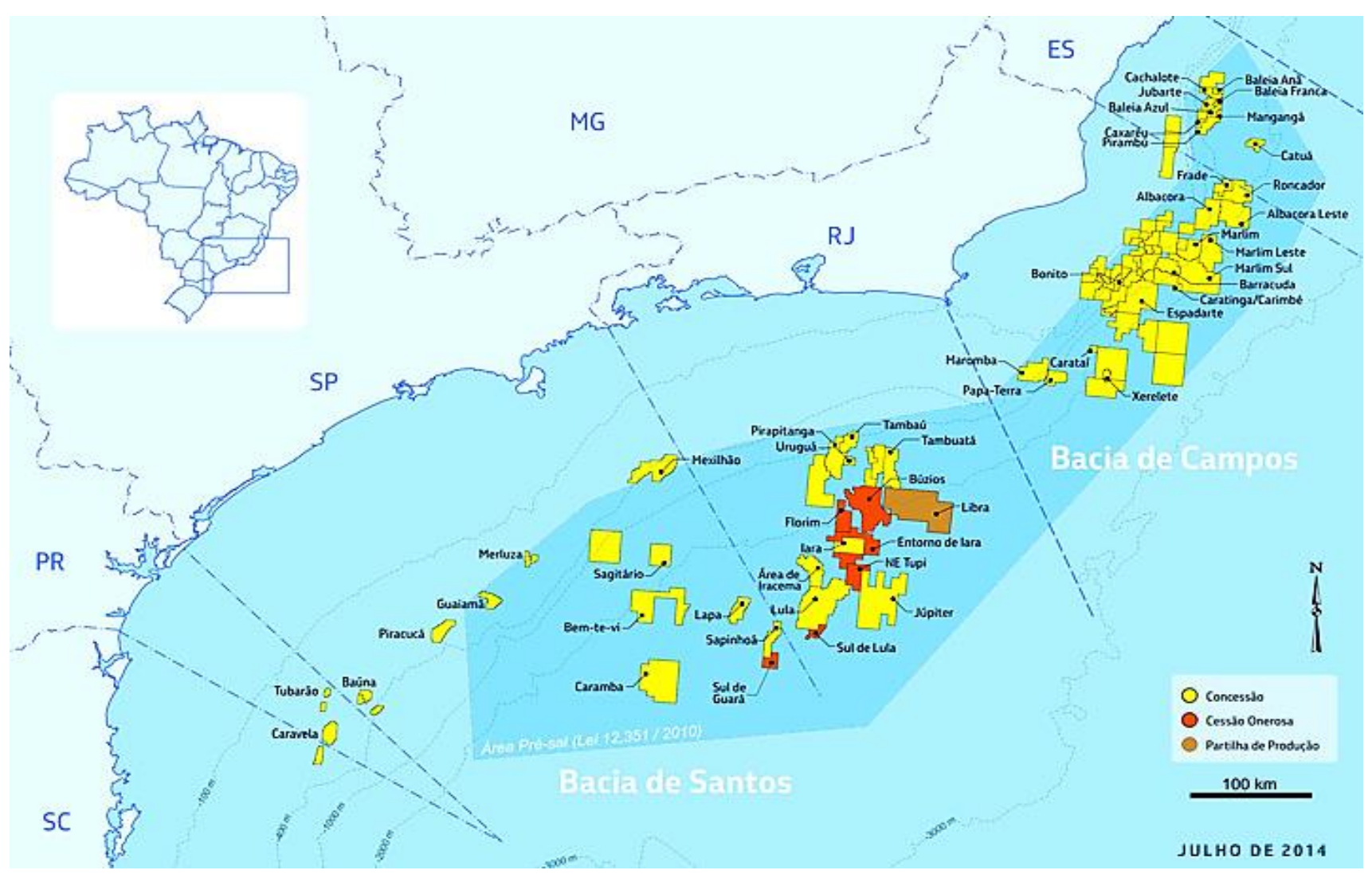

Como referido na Introdução os impactos locais, positivos ou negativos, não se restringem aos efeitos de indústria, pois são também fortemente influenciados pelo recebimento das rendas petrolíferas. Royalties e participações especiais (que incidem apenas sobre os campos de maior produtividade) são pagos pelas petroleiras à União, aos estados e aos municípios. Os principais beneficiários são municípios que confrontam com poços em produção e são definidos como pertencentes à Zona de Produção Principal; municípios limítrofes a estes são definidos como pertencentes à Zona de Produção Secundária e recebem percentuais um pouco menores; ainda fazem jus ao recebimento os municípios que abrigam instalações industriais ligadas ao setor assim como outras instalações, tais como dutos e bases de embarque e desembarque. O principal beneficiário hoje é o Estado do Rio que confronta com as Bacias de Campos e de Santos, as duas maiores bacias offshore do país. 
Para a seleção dos municípios analisados, considerou-se que Niterói, embora sendo o segundo recebedor das rendas petrolíferas, e Rio de Janeiro, não deveriam ser incluídos dado que apresentam economias complexas e diversificadas, sendo o setor petrolífero relativamente de pequena relevância em sua dinâmica econômica. O município de Cabo Frio não foi selecionado uma vez que sua economia é altamente influenciada pela atividade turística e de veraneio, assim como pela presença de um aeroporto de porte internacional ${ }^{2}$. São João da Barra, na atualidade, tem sua dinâmica econômica determinada pela presença do Complexo Industrial e Portuário do Açu. ${ }^{3}$

Deste modo, serão analisados: Campos dos Goytacazes, Macaé, Rio das Ostras, Maricá, Angra dos Reis e Paraty.

O período analisado está compreendido entre os anos de 2000 até o presente, no qual serão levantados dados referentes aos anos: 2000; 2010 e 2018. No ano de 2000 a exploração no pré-sal não havia iniciado, sendo então possível se ter um retrato da distribuição espacial do setor no estado ainda sob a influência exclusiva da Bacia de Campos; o ano de 2010 é analisado uma vez que de fato é a partir da Lei n.12.351/2010, que a exploração nos campos do pré-sal passam a ter relevância. E 2018 por ser o último ano de que se dispõe de dados completos de modo a comparar com os anos anteriores.

Justificar a relevância do emprego em um país que apresenta na atualidade um contingente de desempregados da ordem de 13 milhões de pessoas aos quais se somam 37 milhões de trabalhadores em trabalho informal, constituindo um gigantesco contingente de 50 milhões de trabalhadores subutilizados, enquanto os empregos formais no setor privado são apenas 33 milhões é redundante (DOWBOR, 2019). Embora o setor petrolífero não seja altamente empregador, dado o nível de sofisticação tecnológica de suas atividades, é um dos setores que permanece em crescimento mesmo na atual fase de recessão da economia nacional.

Para os anos indicados serão levantados dados sobre: (i) população residente nos municípios por situação de domicílio e taxas de crescimento; (ii) postos de trabalho por setores de atividade econômica, que funcionarão como proxi da localização de equipamentos industriais voltados à produção do setor petrolífero localizados nas áreas estudadas e (iii) nível educacional.

\footnotetext{
2 O Aeroporto Internacional de Cabo Frio contribui com uma significativa parcela dos impostos municipais arrecadados no município, pois a ampliação dele possibilitou a instalação de diversas empresas prestadoras de serviços na área de logística, importação e exportação, transporte, recepção de turistas, alimentação, catering entre outras. Deste modo, promoveu mudanças na estrutura econômica do município, tornando-se um importante gerador de emprego e renda (CARVALHO, 2014).

${ }^{3}$ Maiores informações sobre São João da Barra e o Porto do Açu podem ser obtidas no artigo publicado no presente livro intitulado "Fluxos transnacionais e espaços em reconversão econômica: análise do caso de município de São João da Barra" de autoria de PIQUET, CARNEIRO e CASTRO.
} 
Os dados são baseados na Classificação Nacional de Atividades Econômicas, CNAE do IBGE. O subsetor econômico Extrativa Mineral que se insere na seção “Indústria Extrativa” de acordo CNAE 2.0, compreende:

As atividades de extração de minerais em estado natural: sólidos (carvão e outros minérios), líquidos (petróleo cru) e gasosos (gás natural), podendo realizar-se em minas subterrâneas, a céu aberto ou em poços. Inclui as atividades complementares de beneficiamento associado à extração, realizadas principalmente para melhorar a qualidade do produto e facilitar a comercialização, desde que o beneficiamento não altere as características físicas ou químicas dos minerais. As atividades de beneficiamento são, geralmente, executadas pela empresa mineradora junto ao local da extração. São consideradas atividades de beneficiamento: trituração, classificação, concentração, pulverização, flotação, liquefação de gás natural, etc. Esta seção compreende também os serviços industriais realizados sob contrato que fazem parte do processo produtivo das atividades desta seção, particularmente na extração de petróleo, e as atividades especializadas de apoio à exploração mineral.

É importante registrar que dentro dessa seção, está contida a divisão Extração de Petróleo e Gás Natural, que compreende as seguintes atividades:

[...] extração de petróleo e gás natural e a extração de xisto e de areias betuminosas. Esta divisão compreende também as atividades de preparação e operação dos campos de petróleo e de gás, tais como: perfuração dirigida e reperfuração, perfuração inicial, reparação e desmantelamento de torres de perfuração, cementação dos tubos dos poços e todas as atividades de preparação do petróleo e gás realizadas no local pelos operadores de poços até o momento da remessa para fora do campo de petróleo, realizadas no local, pelos operadores de poços. (CNAE 2.0)

Esse conjunto de subsetores não engloba todas as atividades ligadas ao setor petrolífero, estando fora deste levantamento a produção da indústria fornecedora de máquinas e equipamentos, os estaleiros e as empresas prestadoras de serviços. Essa restrição se impôs tendo em vista que não seria possível estabelecer o corte entre a produção geral dessas empresas e à destinada ao setor. Além disso, sua localização é dispersa por outros estados brasileiros e até mesmo no exterior, sendo que é na indústria fornecedora (também chamada de para-petrolífera) onde residem os efeitos mais significativos para o desenvolvimento de um dado país ou região. Este segmento compreende fabricantes de equipamentos, montagem industrial, estaleiros, firmas de projetos de engenharia, logística assim como centros de pesquisa. O levantamento desse tipo de dado exige pesquisa de campo complexa e de longa duração.

Com o intuito de estimar o impacto das atividades da Petrobras sobre o desenvolvimento produtivo e tecnológico de seus fornecedores no Brasil, o IPEA coordenou um amplo estudo envolvendo pesquisadores vinculados ao próprio instituto e a PUC-RS, UFF, UFPR, UFMG, UFRJ, UFU, UnB, UNICAMP e USP, abrangendo informações oriundas de 69.874 empresas que forneceram bens e serviços para empresa ao logo de 10 anos - entre 1998 e 2007 -, analisando variáveis como exportações, produtividade e geração de emprego no Brasil (DE NEGRI et al., 2011). 
As diferenças econômicas entre os municípios do norte fluminense e os do sul do estado são marcantes. Enquanto os do Norte Fluminense, quando do início da exploração e produção em seu litoral encontravam-se em fase de profunda decadência econômica e social, o que tornou as atividades petrolíferas um novo e forte vetor de mudança regional - sejam as causadas pelas atividades ligadas à indústria petrolífera propriamente dita, seja a demanda ampliada derivada dos altos salários pagos pelo setor, sejam os benefícios derivados do recebimento de royalties e das participações especiais - ao sul o quadro é diverso. Os municípios selecionados pertencem a mesorregiões distintas, têm um perfil econômico diferenciado e só em anos recentes passam a ser incluídos no rateio das rendas do setor.

Campos dos Goytacazes, Macaé e Rio das Ostras são confrontantes à Bacia de Campos e desde os anos 1976 encontram-se sob forte influência do setor petrolífero: Campos dos Goytacazes, maior município do interior do estado, por ser confrontante com numerosos campos produtores; Macaé por ser a principal base de apoio terrestre da exploração offshore e Rio das Ostras que por ser limítrofe ao município de Macaé passou a receber um contingente populacional não só em busca de novas oportunidades de trabalho, como também devido aos menores custos de moradia que os verificados em Macaé e passa então a receber a migração de pessoal já ocupado em Macaé. Além disso, a administração pública municipal instala em seu território um distrito industrial voltado às atividades petrolíferas.

Maricá, Angra dos Reis e Paraty só a partir da exploração do pré-sal passaram a figurar nas análises sobre o setor em função dos recebimentos de significativas somas de rendas petrolíferas. Maricá, pertencente à Região Metropolitana do Rio de Janeiro, até recentemente era desconhecido e pouco tem a oferecer aos seus habitantes em termos de mercado de trabalho. Angra do Reis, pertencente à Região Costa Verde, abriga não só um dos maiores portos ${ }^{4}$ do país, exportador e importador de petróleo - tendo como principal função as atividades de apoio offshore e de embarque e desembarque de óleo e gás devido à proximidade com as bacias produtoras de Campos e Santos, além das refinarias de Duque de Caxias e do Complexo Petroquímico do Rio de Janeiro, Comperj, ainda em fase de construção - como também importante estaleiro. ${ }^{5}$

Paraty apresenta perfil econômico não relacionado ao petróleo - as principais atividades da cidade são a pesca, o comércio, a indústria de aguardente, a agricultura, o artesanato e principalmente o turismo.

Estima-se que o fluxo anual de turistas em Paraty varia de 250 a 300 mil, sendo o quarto município brasileiro que mais recebe turistas estrangeiros, e o segundo polo turístico do país (MORAES ZOUAIN et al.,

\footnotetext{
4 Trata-se de um porto público, sob administração da Cia Docas do Rio de Janeiro, que foi arrendado à iniciativa privada em 2009 à empresa Technip Brasil que também opera no Porto do Açu, ao norte do Estado do Rio. Em 1970 torna-se exportador de produtos siderúrgicos da Cia Siderúrgica Nacional, CSN e importador de trigo, então um dos produtos que mais oneravam a pauta de importação brasileira.

${ }^{5} \mathrm{O}$ estaleiro já construiu os semissubmersíveis P51 e P52, unidades flutuantes de armazenagem e transferência de petróleo, sendo o navio-plataforma Cidade de Ilha Bela, o FPSO, aí construído com capacidade de armazenar em seus tanques 1,6 milhões de toneladas de barris de petróleo e de alojar 140 pessoas. Fonte: Plano Mestre do Porto de Angra dos Reis, maio de 2015
} 
2011). Além disso, recebeu, em julho de 2019, o honroso título de Patrimônio da Humanidade, concedido pela Unesco. Contudo, sua localização geográfica Ihe confere posição elevada na lista dos recebedores de royalties e participações especiais.

O rateio das rendas petrolíferas entre os beneficiários é conduzido pela ANP segundo complexas regras de distribuição que definem o "motivo enquadramento" dos municípios selecionados, como apresentado no Quadro 1.

Quadro 1. Motivos de enquadramento segundo a ANP

Fonte: ANP: SPG VOL. XI (Revisão, agosto/2014) Manual de Vistoria, Cadastramento e Auditoria de Instalações de Embarque e Desembarque de Petróleo e Gás Natural). Elaborado por Paula Nazareth em agosto de 2019.

\begin{tabular}{|c|c|c|c|c|c|}
\hline \multirow{4}{*}{ Municípios } & \multicolumn{5}{|c|}{ Motivo enquadramento - mar } \\
\hline & \multicolumn{2}{|c|}{ Até $5 \%$} & \multicolumn{3}{|c|}{$>5 \%$} \\
\hline & \multirow{2}{*}{$\begin{array}{c}\text { Zona } \\
\text { principal }\end{array}$} & \multirow{2}{*}{ Instalação ${ }^{6}$} & \multirow{2}{*}{$\begin{array}{c}\text { Municípios } \\
\text { Confrontantes }\end{array}$} & \multicolumn{2}{|c|}{ Afetados ${ }^{7}$} \\
\hline & & & & Instalação & $\begin{array}{c}\text { Zona de } \\
\text { influências }\end{array}$ \\
\hline Angra dos Reis & $x$ & $x$ & & $x$ & \\
\hline C. dos Goytacazes & $x$ & $x$ & $x$ & $x$ & \\
\hline Macaé & $x$ & $x$ & $x$ & $x$ & \\
\hline Maricá & $x$ & & $x$ & & \\
\hline Paraty & $x$ & & $x$ & & $x$ \\
\hline Rio das Ostras & $x$ & & $x$ & & \\
\hline
\end{tabular}

Como se observa, todos os municípios analisados são integrantes da Zona de Produção Principal, contudo a composição das rendas petrolíferas entre royalties de participações especiais difere de município a município e no caso em tela são assim compreendidos:

- a maior parte recebida por Angra dos Reis é proveniente dos royalties da parcela de até $5 \%$ referente aos equipamentos neles localizados, por ter em seu território o maior porto exportador do Estado do Rio, com 49\% do total das exportações fluminenses, sendo o petróleo o principal produto exportado, além de contar com um importante estaleiro. Contudo, não recebe participações especiais por não ser confrontante.

\footnotetext{
${ }^{6}$ Percentual de $10 \%$ da parcela de $5 \%$ dos royalties a serem distribuídos aos municípios onde se localizam as instalações de embarque e desembarque (Lei no 7.990/89) independe do volume movimentado.

${ }^{7}$ Afetados por instalações de embarque e desembarque (Lei no 9.478/97) fazem jus a 7,5\% da parcela acima de $5 \%$ dos royalties, segregados por origem, de todo o País, distribuídos proporcionalmente ao volume de petróleo e gás natural movimentado na instalação.

${ }^{8}$ Se a instalação for aquática (monoboias, quadros de boias múltiplas, quadros de âncoras, píeres de atracação, cais acostáveis), os royalties da parcela acima de $5 \%$ são divididos entre o município afetado diretamente, onde se localiza a instalação de embarque e desembarque, que recebe $40 \%$ do montante de royalties da instalação, e $60 \%$ para os municípios da zona de influência da instalação de embarque e desembarque.
} 
- Macaé, por ser a principal base de apoio à produção offshore, além de abrigar em seu território a Termelétrica Usina Mario Lago, o Terminal Terrestre de Cabiúnas e oleodutos é da parcela de até 5\% seus maiores recebimentos. Como tem confrontação com campos maduros, a parcela superior $5 \%$ é pouco significativa.

- Campos dos Goytacazes, tem apenas uma pequena base de pouso e decolagem de helicópteros, mas é confrontante com 35 campos produtores de elevada produtividade, o que lhe garante lugar de destaque nos recebimentos.

- Paraty: recebe royalties excedentes por fazer confrontação com três campos e estar na zona de influência de Angra. Não recebe participações especiais;

- Maricá por ser confrontante com 10 campos que têm elevada produtividade recebe participações especiais, sendo que quase $90 \%$ dos royalties recebidos são provenientes do campo de Lula e também recebeu elevadas participações especiais.

- Rio das Ostras, com 16 campos confrontantes, recebe pagamentos por excedentes sendo que $26 \%$ do que recebeu no ano de 2018 é proveniente de participações especiais, segundo dados fornecidos por NAZARETH (2019).

\section{A produção em águas profundas e ultraprofundas}

Antes de analisarmos os impactos da indústria petrolífera nos territórios sob sua influência cabe uma breve análise sobre o desenvolvimento da produção de petróleo e gás nas respectivas áreas de produção.

Os primeiros trabalhos de sísmica exploratória no Brasil têm início ainda na década de 1950. A incipiência técnica nesse período, contudo, limitava sua aplicação às investigações em terra ou em águas de pequena profundidade. É só no início dos anos 1960 que a Petrobras inicia pesquisa exploratória em mar aberto e, no início da década de 1970, a tecnologia já permitia efetuar levantamentos em águas de profundidade de até 200 metros - naquela época considerada "águas profundas". O poço pioneiro 1-RJS-9A, situado em profundidade de 100 metros, viria a se constituir no descobridor de petróleo na plataforma continental brasileira, dando início às descobertas na Bacia de Campos. Esse poço deu origem ao campo de Garoupa (CAETANO FILHO, 2003, p. 51).

As pesquisas para exploração em Garoupa levaram a uma inovação: instalação de sistemas de produção antecipada sobre plataformas flutuantes, reduzindo de quatro anos para meses, o prazo mínimo estimado para iniciar a produção. Garoupa foi um salto para o mercado brasileiro que, na época, produzia apenas 10 mil barris por dia. Segundo as palavras de Caetano Filho: 
A produção comercial na Bacia de Campos começaria em agosto de 1977 em águas de 127 metros de profundidade e com vazão de 10.000 barris de óleo por dia, nesta produção foi adotada a referida concepção de um Sistema de Produção Antecipada (SPA) instalado no convés de uma unidade flutuante. (CAETANO FILHO, 2003, p.52)

Com as descobertas na Bacia de Campos, a Petrobras intensificou a busca por conhecimento para tornar viável a produção de petróleo em águas cada vez mais profundas. O desenvolvimento de pesquisas na área offshore passou a ser vital para a empresa que não só funda o Centro de Pesquisas da Petrobras - Cenpes, até hoje o mais importante centro de pesquisas do setor, como também intensifica laços de colaboração com a Coordenação de Pós Graduação em Engenharia - COPPE/UFRJ e com numerosos laboratórios de pesquisas no Brasil e no exterior.

Desde então a pesquisa tecnológica em águas profundas torna-se a marca de sucesso da empresa, pois se para as águas ditas "rasas" a Petrobras detinha conhecimentos, para a exploração dos campos gigantes de Albacora, Marlim e Barracuda, descobertos nos anos de 1980 em águas de profundidades superiores a $400 \mathrm{~m}$, tornou-se imperativa a descoberta de sistemas completamente novos e inovadores, uma vez que não havia paralelos em outras localidades do mundo que pudessem possibilitar eventuais transferências tecnológicas (CAETANO FILHO 2003 p. 60). O êxito das pesquisas desenvolvidas garantiu à Bacia de Campos o título de "joia da coroa" do setor petrolífero brasileiro, de onde provinha praticamente a totalidade do petróleo produzido no país.

Em 2006/2007 a Petrobras divulga seu grande e novo resultado nas pesquisas que vinha desenvolvendo: a descoberta de ricas jazidas de petróleo em uma camada ainda mais profunda, nas áreas do pré-sal, em águas ultraprofundas, localizadas no chamado polígono do pré-sal confrontante com os Estados do Rio, São Paulo e Espírito Santo. Os desafios para tal produção eram muitos e exigiam soluções simultâneas: na área tecnológica tratava-se de tecnologia ainda não desenvolvida; na área financeira, em decorrência do grande volume de investimentos exigidos; quanto à gestão, devido ao volume de novos projetos implantados simultaneamente e, quanto à logística, em decorrência da distância.

Gradualmente, o foco dos investimentos do setor se desloca para esta nova fronteira produtiva. A princípio de modo tímido, sob o argumento de que os custos da E\&P nesse nível de profundidade inviabilizaria sua produção em grande escala. Contudo, o avanço tecnológico e o jogo geopolítico internacional logo demonstraram que a produção nesta nova área era não só viável - dada a rápida expansão da produção, que pode ser constatada observando a Figura 2 -, como altamente lucrativa. A Petrobras buscando maior rentabilidade redireciona seus investimentos dos campos maduros, em declínio, da Bacia de Campos para os novos campos, de maior produtividade na área do pré-sal. ${ }^{9}$

\footnotetext{
${ }^{9}$ Embora pesquisas da Petrobras desde 2006 indicassem que as descobertas de reservas no chamado polígono do pré-sal teriam impacto nas reservas provadas do país que levariam a mudanças profundas na dinâmica exploratória, os testes de longa duração
} 
Figura 2. Produção de Petróleo no Pré-sal - 2014 e 2018 (bbl/dia $\left.{ }^{10}\right)$

Fonte: Elaboração própria utilizando dados da ANP/SIGEP Produção (2019)

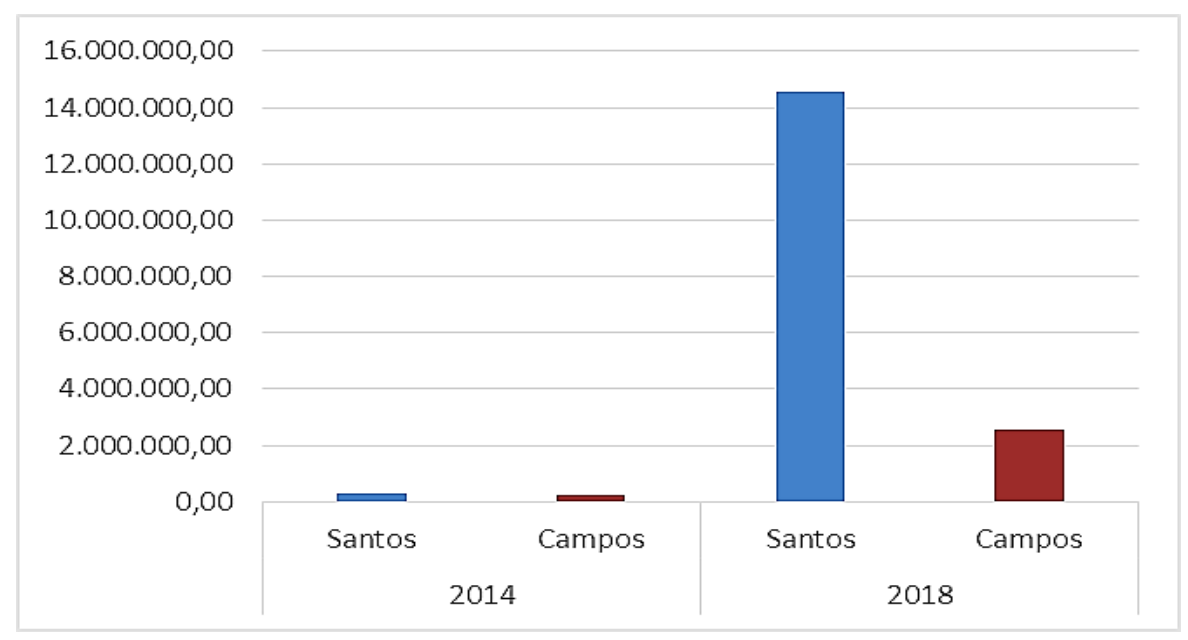

Transcorridos 22 anos após a perda de monopólio da Petrobras, ela continua sendo a maior produtora de petróleo no Brasil, como pode ser observado na Figura 3, tendo arcado com a maior parte dos investimentos e pesquisas que permitiram a descoberta do atualmente cobiçado petróleo na camada de présal.

Figura 3. Distribuição da produção de petróleo por operador - junho de 2019 Fonte: Boletim da Produção de Petróleo e Gás Natural - ANP - Junho/2019.

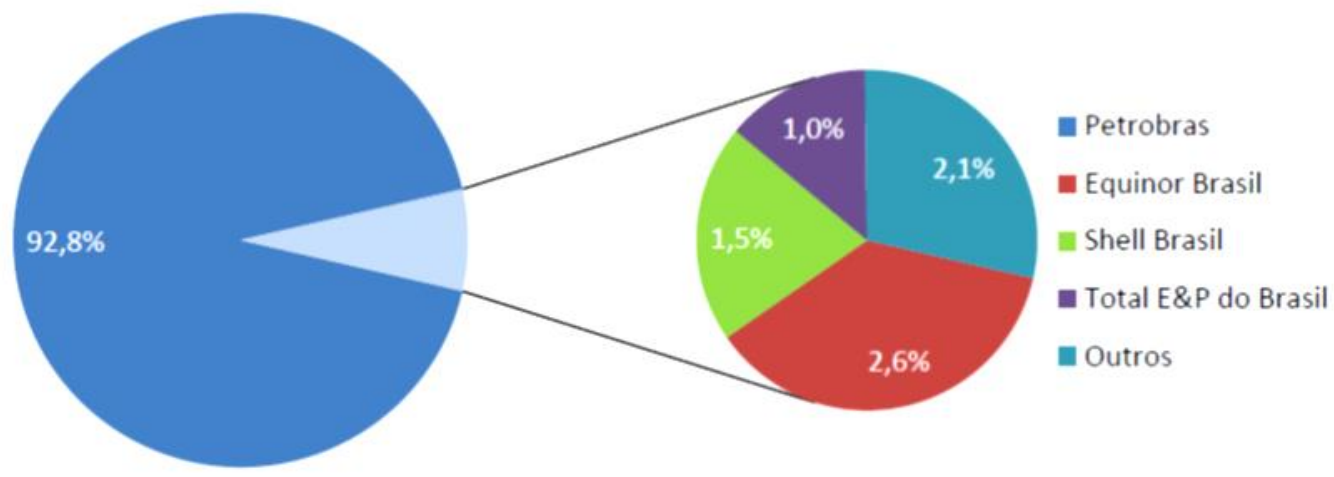

Doze anos após sua descoberta, o pré-sal brasileiro se tornou a fronteira petrolífera mais atraente do mundo, mais competitiva que os badalados shale gas e tight oil - como são chamados o óleo e o gás não convencionais dos Estados Unidos - que chegaram a ser vistos como uma revolução de impacto global. Além disso, os campos de petróleo no pré-sal são extremamente produtivos - fato que pode ser comprovado 
observando a evolução da produção retratada na Figura 4. Segundo Almeida e Ribeiro (2018) o pré-sal é hoje a mais importante região petrolífera do mundo, dadas à elevada produtividade dos poços e a forte redução de custos que vem sendo obtida nos últimos anos. ${ }^{11}$ É a atratividade do pré-sal que vem despertando o crescente interesse de petroleiras do porte da Exxon, Shell, BP, nos últimos leilões da ANP.

Figura 4. Evolução da Produção de Petróleo pré-sal X pós-sal - janeiro 2009 a janeiro de 2019

Fonte: Pré-Sal Petróleo S.A. (PPSA) julho/2019

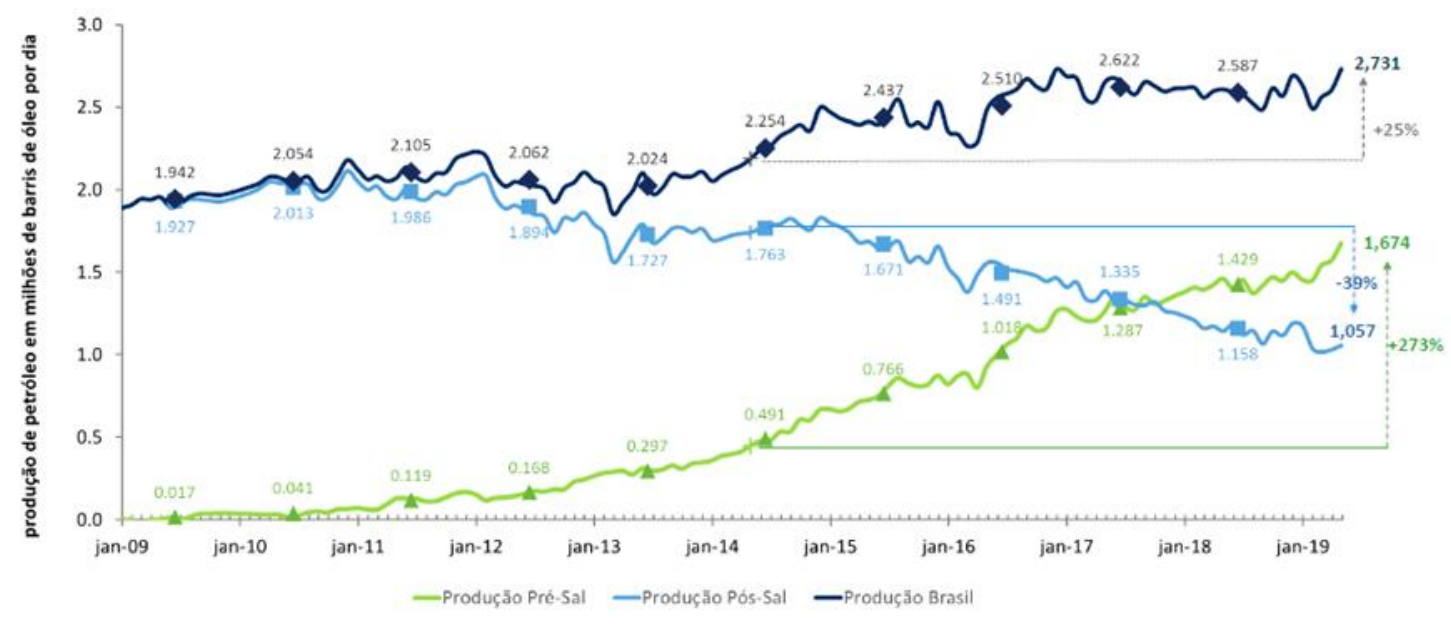

As condições da produção e do estágio de desenvolvimento do País nesses 30 anos que separam as descobertas de petróleo nas duas principais bacias produtoras se diferenciam em numerosos pontos: enquanto a produção na Bacia de Campos ocorre quando a produção offshore estava em seu início, tendo a Petrobras como única operadora em território nacional, seguindo as diretrizes que fundamentaram a sua criação e em um período em que os controles ambientais eram praticamente nulos, a produção na Bacia de Santos se dá em outro momento histórico, com o país apresentando um parque industrial tecnologicamente mais desenvolvido, contando com importantes petroleiras estrangeiras operando no Brasil e controles ambientais mais rígidos.

No cenário internacional o tema do aquecimento global vem ocupando boa parte dos dirigentes dos principais países, destacando-se a urgência quanto a transição para uma economia de baixo carbono. Esta mudança é global, de natureza estrutural e a transição já está em curso. Segundo McGlade e Ekins, (2015 apud PAPATERRA; DUTRA, 2018) três quartos do carvão, metade do gás e um terço do óleo guardados nas jazidas

\footnotetext{
${ }^{11}$ Magda Chambriard, ex-diretora geral da ANP cita o tempo de perfuração de um poço, que passou de um ano e meio para apenas três meses, o que significa uma forte redução de custos uma vez que a diária de uma sonda de exploração custa cerca de US\$ 350 mil por dia.
} 
conhecidas não serão aproveitados até 2050, se a intenção for conter o aquecimento global em até 2 graus centígrados.

Cabe ressaltar, porém, que um dos maiores desafios da transição energética mundial é a substituição do carvão como fonte de energia - fato que foi enfatizado durante a Rio Oil \& Gás 2018. Neste contexto, a transição energética brasileira difere da maioria dos demais países, pois sua matriz energética é altamente diversificada - 43,5\% do consumo de energia no Brasil provém de fontes renováveis, enquanto a média mundial é composta por apenas 14\% (EPE, 2019) ${ }^{12}$. Deste modo, o País deve utilizar os recursos da exploração de petróleo para investir na ampliação do uso de fontes renováveis das quais dispõe.

Diante de tantos desafios, convém analisar os efeitos que a exploração de petróleo produz no âmbito local. No item a seguir serão apresentados indicadores que podem contribuir para a avaliação das mudanças ocorridas nos municípios fluminenses selecionados.

\section{O que os dados indicam}

Inicialmente, foram levantados dados sobre a taxa de crescimento da população residente e sua evolução ao longo do tempo por tratar-se de um importante indicador dos impactos nos territórios municipais, tendo em vista que a perspectiva de oportunidades de trabalho em um país que sofre de uma subutilização crônica de sua mão de obra atrai pessoas de fora do município o que sobrecarrega os serviços públicos de saúde, educação e saneamento básico além de causar alterações no cotidiano da população quanto à mobilidade e segurança.

Os dados da Tabela 2 indicam que, de fato, em todos os municípios estudados o crescimento populacional tanto na primeira década considerada quanto na segunda foi significativamente superior ao do estado e do Brasil. Chama a atenção o grande crescimento populacional de Rio das Ostras na década de 2000, o que pode ser explicado pelas informações já registradas anteriormente. Outro ponto a ser considerado é a grande queda de crescimento entre 2010 e 2018, indicando que o boom petrolífero de fato perdeu vigor, pois a queda é bem menor no estado e no país.

\footnotetext{
${ }^{12}$ A matriz elétrica brasileira é ainda mais renovável do que a energética, pois $82 \%$ provém de fontes renováveis, sendo $65,2 \%$ fontes hidráulicas. Já a matriz energética mundial, 76\% das fontes são não renováveis (EPE, 2019).
} 
Tabela 2. População residente nos municípios selecionados, Estado do Rio de Janeiro e Brasil Fonte: IBGE, Censos Demográficos de 2000 e 2010 e projeção 2018

\begin{tabular}{|c|c|c|c|c|c|c|c|c|c|}
\hline & \multicolumn{3}{|c|}{ Censo 2000} & \multicolumn{3}{|c|}{ Censo 2010} & \multirow{2}{*}{$\begin{array}{c}\text { Estimativa } 2018 \\
\text { Total }\end{array}$} & \multirow{2}{*}{\begin{tabular}{|c}
$2000-2010$ \\
Tx de \\
crescimento \\
Pop. Total \\
$(\%)$
\end{tabular}} & \multirow{2}{*}{\begin{tabular}{|c}
$2010-2018$ \\
Tx de \\
crescimento \\
Pop. Total \\
\end{tabular}} \\
\hline & Total & Urbana & Rural & Total & Urbana & Rural & & & \\
\hline Angra dos Reis & 119.247 & 114.300 & 4.947 & 169.511 & 163.290 & 6.221 & 200.407 & 42 & 18 \\
\hline C. dos Goytacazes & 406.989 & 364.177 & 42.812 & 463.731 & 418.725 & 45.006 & 503.424 & 14 & 9 \\
\hline Macaé & 132.461 & 126.007 & 6.454 & 206.728 & 202.859 & 3.869 & 251.631 & 56 & 22 \\
\hline Maricá & 76.737 & 63.399 & 13.338 & 127.461 & 125.491 & 1.970 & 157.789 & 66 & 24 \\
\hline Rio das Ostras & 36.419 & 34.552 & 1.867 & 105.676 & 99.905 & 5.771 & 145.989 & 190 & 38 \\
\hline Paraty & 29.544 & 14.066 & 15.478 & 37.533 & 27.689 & 9.844 & 42.630 & 27 & 14 \\
\hline Estado do RJ & 14.391 .282 & 13.821 .466 & 569.816 & 15.989 .929 & 15.464 .239 & 525.690 & 17.159 .960 & 11 & 7 \\
\hline Brasil & 169.799 .170 & 137.953 .959 & 31.845 .211 & 190.755 .799 & 160.925 .804 & 29.829 .995 & 208.494 .900 & 12 & 9 \\
\hline
\end{tabular}

Nota: Nos dados de 2018, por serem estimativa, não consta o desmembramento entre Urbano e Rural

A seguir, na Tabela 3, constam os dados sobre o número total de empregos nos municípios estudados, no Estado do Rio e no Brasil, de modo a se ter uma visão de sua magnitude.

Tabela 3. № de postos de trabalho formal e taxa de crescimento nos municípios selecionados, no Estado do RJ e no Brasil Fonte: RAIS/CAGEC - Ministério do Trabalho

\begin{tabular}{lc|c|c|c|c}
\hline & 2000 & 2010 & 2018 & $2000-2010$ & $2010-2018$ \\
\cline { 2 - 6 } & Postos de trabalho & Postos de trabalho & Postos de trabalho & $\begin{array}{c}\text { Tx de evolução } \\
(\%)\end{array}$ & $\begin{array}{c}\text { Tx de evolução } \\
(\%)\end{array}$ \\
\hline Angra dos Reis & 16.999 & 41.166 & 33.739 & 142 & -18 \\
C. dos Goytacazes & 47.741 & 87.380 & 85.067 & 83 & -3 \\
Macaé & 37.975 & 115.775 & 113.791 & 205 & -2 \\
Maricá & 6.340 & 13.034 & 20.524 & 106 & 57 \\
Paraty & 2.894 & 5.842 & 8.471 & 102 & 45 \\
Rio das Ostras & 3.766 & 19.443 & 25.442 & 416 & 31 \\
\hline Estado do RJ & 2.718 .138 & 4.080 .082 & 4.042 .637 & 50 & -1 \\
\hline Brasil & 26.228 .629 & 44.068 .355 & 46.702 .668 & 68 & 6 \\
\hline \multicolumn{2}{c|}{ Obs.: Dados de 2000 e 2010 - RAIS } & & 6
\end{tabular}

Obs. 2: Dados de 2018 - Estoque de 2017 (RAIS) + Saldo 2018 (CAGED)

Ressaltam as taxas de crescimento dos três municípios que têm em seus territórios equipamentos do setor petrolífero, sendo que a magnitude do crescimento do número de postos de trabalho de Rio das Ostras mais uma vez surpreende, sendo seguida de longe por Macaé e Angra dos Reis. A queda vertiginosa observada no decênio posterior é mais aguda em Angra, pois o principal estaleiro localizado no município fechou cerca de 10.000 postos de trabalho entre os anos 2015 e 2017, em decorrência das mudanças ocorridas na política de compras da Petrobras que atingiu profundamente a construção naval brasileira.

O Instituto de Estudos Estratégicos de Petróleo, Gás Natural e Biocombustíveis - INEEP destaca que a Petrobras funciona como motor de geração de empregos e que a redução de seus investimentos, nos últimos 
anos, gerou perdas de 740.000 ocupações, entre 2016 e 2017 em função da redução da demanda sobre a cadeia fornecedora (RAMALHO, 2019).

De Negri et al. (2011) apontam que

\begin{abstract}
O impacto da PETROBRAS sobre seus fornecedores no Brasil é especialmente relevante para o desenvolvimento do Brasil, pois este é um país com mercado interno relativamente grande, quando comparado com a média dos países em desenvolvimento. Por sua vez, deve ser recordado que a sustentabilidade do seu crescimento no médio e longo prazo depende da geração de conhecimento novo e da capacidade de transformar este conhecimento em novos produtos e processos, ou seja, da capacidade de gerar inovações tecnológicas. Não se deve supor que apenas o conhecimento importado nas máquinas e equipamentos ou em pacotes tecnológicos dos países tecnologicamente mais avançados seja suficiente para sustentar um crescimento mais acelerado da economia brasileira (DE NEGRI et al., 2011, p. 16).
\end{abstract}

Ao se analisar, na Tabela 4, a distribuição entre os subsetores pertencentes ao setor petrolífero, verificase que os postos de trabalho estão altamente concentrados em Macaé com 98\% em 2010 e $93 \%$ em 2018, seguido com grande distância por Rio das Ostras com respectivamente 2\% e 6\%. Em Extração de Petróleo e Gás Natural e Atividades de Apoio à Extração de Petróleo e Gás Natural esses dois municípios detêm a totalidade dos empregos. Angra dos Reis já teve participação no subsetor de Fabricação de máquinas e equipamentos para prospecção e extração de petróleo, peças e acessórios, mas perde essa oferta de postos de trabalho a partir de 2010, mantendo apenas uma pequena participação em atividades de apoio à extração de petróleo e gás natural.

Tabela 4. Distribuição do estoque de emprego no setor petrolífero por subsetores nos municípios selecionados Fonte: RAIS/CAGEC - Ministério do Trabalho

\begin{tabular}{|c|c|c|c|c|c|c|c|c|c|c|c|c|c|c|c|c|c|c|}
\hline \multirow{2}{*}{ Subclasse de setores CNAE 2.0} & \multicolumn{3}{|c|}{ C. dos Goytacazes } & \multicolumn{3}{|c|}{ Macaé } & \multicolumn{3}{|c|}{ Rio das Ostras } & \multicolumn{3}{|c|}{ Maricá } & \multicolumn{3}{|c|}{ Angra dos Reis } & \multicolumn{3}{|c|}{ Paraty } \\
\hline & 2000 & 2010 & 2018 & 2000 & 2010 & 2018 & 2000 & 2010 & 2018 & 2000 & 2010 & 2018 & 2000 & 2010 & 2018 & 2000 & 201 & 2018 \\
\hline $\begin{array}{l}\text { Extração de petróleo e gás } \\
\text { natural }\end{array}$ & 0 & 0 & 0 & 2.145 & 15.007 & 10.121 & 0 & 39 & 888 & 0 & 0 & 0 & 0 & 70 & 0 & 0 & 0 & 0 \\
\hline $\begin{array}{l}\text { Atividades de apoio à extração } \\
\text { de petróleo e gás natural }\end{array}$ & 0 & 2 & 0 & 2.250 & 11.614 & 9.113 & 0 & 182 & 235 & 0 & 0 & 0 & 0 & 0 & 226 & 0 & 0 & 0 \\
\hline $\begin{array}{l}\text { Fabricação de produtos do refino } \\
\text { de petróleo }\end{array}$ & 0 & 0 & 0 & 0 & 0 & 0 & 0 & 0 & 0 & 0 & 0 & 0 & 0 & 0 & 0 & 0 & 0 & 0 \\
\hline $\begin{array}{l}\text { Fabricação de outros produtos } \\
\text { derivados do petróleo, exceto } \\
\text { produtos do refino }\end{array}$ & 0 & 0 & 0 & 0 & 19 & 0 & 0 & 0 & 0 & 0 & 0 & 0 & 0 & 0 & 0 & 0 & 0 & 0 \\
\hline $\begin{array}{l}\text { Fabricação de máquinas e } \\
\text { equipamentos para a prospecção } \\
\text { e extração de petróleo, peças e } \\
\text { acessórios }\end{array}$ & 0 & 0 & 0 & 229 & 1.421 & 928 & 0 & 278 & 378 & 0 & 0 & 0 & 740 & 0 & 0 & 0 & 0 & 0 \\
\hline $\begin{array}{l}\text { Manutenção e reparação de } \\
\text { máquinas e equipamentos para a } \\
\text { prospecção e extração de } \\
\text { petróleo }\end{array}$ & 0 & 4 & 0 & 0 & 1.996 & 3.263 & 0 & 2 & 0 & 0 & 0 & 0 & 0 & 0 & 0 & 0 & 0 & 0 \\
\hline Total $(100 \%)$ & 0 & 6 & 0 & 4.624 & 30.057 & 23.425 & 0 & 501 & 1.501 & 0 & 0 & 0 & 740 & 70 & 226 & 0 & 0 & 0 \\
\hline
\end{tabular}

Obs.: Dados de 2000 - RAIS - CNAE 95/Grupo

Obs. 2: Dados de 2010 - RAIS - CNAE 2.0/Subclasse

Obs. 3: Dados de 2018 - Estoque de 2017 (RAIS) + Saldo 2018 (CAGED) - - CNAE 2.0/Subclasse 
Maricá, Paraty e Campos dos Goytacazes não detêm empregos em quaisquer dos subsetores, fazendo jus ao recebimento das rendas petrolíferas por serem municípios confrontantes a campos de alta produtividade. Cabe destaque o caso de Maricá, que atualmente é o maior beneficiado no país pelas rendas petrolíferas pagas pela exploração do campo de Lula, hoje o maior produtor nacional, localizado no pré-sal da Bacia de Santos. O município recebe 50\% dos pagamentos referentes a este campo (NAZARETH et al, 2018, pag.171).

A escolaridade é um dos mais relevantes indicadores quanto às perspectivas de desenvolvimento sustentado de um país sendo que no universo da indústria do petróleo a qualificação da mão de obra é o requisito mais essencial na seleção de pessoal. Sabe-se também que a melhoria da formação de uma dada população só ocorre em períodos de médio e longo prazo e, por essa razão os dados selecionados são referentes apenas aos anos de 2000 e 2018 por ser um intervalo de tempo no qual seria possível haver alguma melhoria nos níveis educacionais.

No Brasil são arrasadores os resultados do Indicador de Alfabetismo Funcional: 57\% das pessoas com ensino médio no País estão no nível básico de alfabetismo, cujas habilidades não contemplam a leitura de textos mais longos, a comparação e a avaliação de informações e a resolução de problemas envolvendo percentuais, proporções, além da interpretação de tabelas de dupla entrada, mapas, gráficos e imagens (PASTORE, 2000).

Por essa razão, na montagem da tabela referente ao nível de escolaridade dos municípios optou-se por considerar apenas dois níveis: o que agregasse Analfabetos, Fundamental Incompleto e Fundamental Completo, que (provavelmente) estariam fora do mercado de trabalho do setor e o outro, agregando Médio Completo e Superior Completo. Mais uma vez o destaque se dá nos municípios de Macaé e Rio das Ostras, cujos resultados confirmam as exigências do setor quanto à qualificação da mão de obra.

Tabela 5. Distribuição dos trabalhadores formais por nível de escolaridade nos munípios selecionados e no Estado do RJ Fonte: RAIS/CAGEC - Ministério do Trabalho

\begin{tabular}{|c|c|c|c|c|c|c|c|c|}
\hline & \multicolumn{4}{|c|}{$\begin{array}{c}\text { Analfabeto } \\
\text { Fundamental Incompleto } \\
\text { Fundamental Completo }\end{array}$} & \multicolumn{4}{|c|}{$\begin{array}{l}\text { Médio Completo } \\
\text { Superior Completo }\end{array}$} \\
\hline & \multicolumn{2}{|c|}{2000} & \multicolumn{2}{|c|}{2018} & \multicolumn{2}{|c|}{2000} & \multicolumn{2}{|c|}{2018} \\
\hline & $\begin{array}{l}\mathrm{N}^{\circ} \mathrm{de} \\
\text { trabal. }\end{array}$ & $\begin{array}{c}\text { Partic. } \\
(\%)\end{array}$ & $\begin{array}{l}\mathrm{N}^{\circ} \text { de } \\
\text { trabal. }\end{array}$ & $\begin{array}{c}\text { Partic. } \\
(\%)\end{array}$ & $\begin{array}{l}\mathrm{N}^{\circ} \text { de } \\
\text { trabal. }\end{array}$ & $\begin{array}{c}\text { Partic. } \\
(\%)\end{array}$ & $\begin{array}{l}\mathrm{N}^{\circ} \mathrm{de} \\
\text { trabal. }\end{array}$ & $\begin{array}{c}\text { Partic } \\
(\%)\end{array}$ \\
\hline Angra dos Reis & 13.011 & 77 & 11.369 & 34 & 3.988 & 23 & 22.254 & 66 \\
\hline C. dos Goytacazes & 30.447 & 64 & 22.698 & 27 & 17.294 & 36 & 61.456 & 72 \\
\hline Macaé & 22.965 & 60 & 14.079 & 12 & 15.010 & 40 & 99.175 & 87 \\
\hline Maricá & 4.208 & 66 & 5.908 & 29 & 2.132 & 34 & 14.569 & 71 \\
\hline Paraty & 1.979 & 68 & 3.043 & 36 & 915 & 32 & 5.413 & 64 \\
\hline Rio das Ostras & 2.232 & 59 & 4.351 & 17 & 1.534 & 41 & 21.020 & 83 \\
\hline Est. do RJ & 1.543 .664 & 57 & 1.012 .658 & 25 & 1.174 .474 & 43 & 3.029 .979 & 75 \\
\hline
\end{tabular}

Obs. 2: Dados de 2018 - Estoque de 2017 (RAIS) + Saldo 2018 (CAGED) 


\section{Um balanço}

A verdadeira contribuição positiva do setor industrial no desenvolvimento tem caráter mais qualitativo que quantitativo, pois além das inúmeras interações que estabelece com os demais setores, é o emprego industrial o mais formalizado. Enquanto em 2018 na indústria de transformação 63\% das pessoas empregadas ocupavam uma vaga com carteira assinada, no comércio esse percentual era de $46 \%$ e nos serviços de $40 \%$. Em alguns ramos industriais como é o caso dos derivados do petróleo atinge 96\% com carteira assinada (IEDI, 2019). Outra contribuição positiva é o fato de que suas atividades, por exigirem maior qualificação profissional, tornam estratégica a retenção de profissionais especializados com salários acima da média geral da indústria. Uma vez que quanto maior é a intensidade tecnológica dos ramos industriais maior serão seus efeitos multiplicadores nos demais setores econômicos de um país, o caso da indústria petrolífera se destaca, dado o elevado nível exigido de sua mão de obra.

Pelos dados apresentados no item anterior nota-se que o perfil econômico dos municípios analisados é bastante diferenciado. Enquanto os municípios do Norte Fluminense, especialmente Macaé e Rio das Ostras apresentam indicadores de melhor qualidade nas variáveis que foram selecionadas e Campos dos Goytacazes se mantém com destaque na oferta de prestação de serviços, os demais municípios pouco mudaram em relação ao seu passado recente, quando ainda não se encontravam sob a influência do setor petrolífero. ${ }^{13}$

Tornou-se fato de grande repercussão na imprensa que os municípios do Norte Fluminense, durante anos os maiores beneficiários, não traduziram os recursos recebidos em diversificação da economia, nem em transformações sociais. Ao contrário, os recursos foram aplicados em grande medida em obras custosas e de pouco ou nenhum alcance econômico, no emprego na administração municipal e, ainda, para fins de pagamento ao funcionalismo foram empenhados recursos futuros. Para citar um exemplo importante, segundo Cruz (2016) "os indicadores de desempenho dos municípios na educação fundamental situam o município de Campos entre as duas últimas colocações nos últimos anos, alternando o último e o penúltimo lugares. Contudo, Campos é um dos municípios que mais recebe royalties do petróleo no Brasil além de ser o 19 maior PIB do País, segundo o IBGE, com base no Censo de 2010”. (CRUZ, 2016, p. 42).

É natural, portanto, que os critérios de repasse das rendas fossem altamente questionados pelos não recebedores, pois a distribuição pelas unidades federativas é muito desigual: apenas 17\% dos 5.570 municípios do país recebem royalties e participações especiais, sendo que os principais beneficiários estão localizados no Estado do Rio. Em 2012, o Congresso aprovou a Lei 12.734/2012 que alterou as regras de rateio em favor dos

\footnotetext{
13 Maricá já convive com as transformações do petróleo: é o município com maior receita das rendas petrolíferas do país, sendo que 70\% do orçamento municipal são recursos provenientes do petróleo. Em reportagem de o Globo de 17-07-2019, Maricá, com orçamento de $\mathrm{R} \$ 2,5$ bilhões, a administração municipal aposta em obras públicas para dinamizar a economia da cidade. A prefeitura anuncia que a meta é asfaltar $350 \mathrm{~km}$ de ruas ainda em 2019, enquanto a rede de esgoto é restrita a 4\% da população. Assim, a obra do Hospital Municipal, após a aplicação de R\$ 40 milhões e praticamente pronta, está embargada desde 2016 à espera da construção da estação de tratamento de esgoto.
} 
demais entes federativos, contudo, o governo do Estado do Rio entrou com recurso no STF e até hoje os efeitos da lei encontram-se suspensos.

A legislação brasileira referente à distribuição das rendas petrolíferas apresenta peculiaridades extravagantes: conforme explicitado no texto, a atividade petrolífera não gera empregos em certos municípios, mas mesmo assim estes são beneficiados por serem confrontantes com jazidas localizadas em seu litoral. Deste modo ocorrem contradições (ou injustiças) como no caso de Macaé que é praticamente o único município que tem em seu território pesados investimentos do setor causando impactos positivos e negativos e recebe menos que Maricá, pois não foi abençoado por Deus ou pela legislação com um campo de alta produtividade em seu litoral! Deste modo, os municípios que não têm em seu território instalações da indústria de petróleo e gás usufruem apenas dos bônus e não dos ônus desta indústria. Se as administrações públicas locais aplicam de modo inadequado os fartos recursos que lhe são repassados, sem que representem melhorias para as populações locais, estas são questões não específicas ao setor petrolífero ou das empresas que nele operam.

O mesmo acaso geológico que favoreceu a Região Norte Fluminense, abençoada pela grande concentração de jazidas em seu litoral, agora parece dar cartas bem menos favoráveis. A Bacia de Campos ainda representa parte expressiva e fundamental da produção nacional de óleo e gás do País, porém nela predominam os chamados "campos maduros", aqueles com mais de 25 anos de produção ou que tenham atingido $70 \%$ da estimativa de produção. Em levantamento realizado pela ANP 54\% desses campos encontramse concentrados na Bacia de Campos. (ROCKMANN, 2019).

A redução da produção de petróleo, no pós-sal, na bacia de Campos e o aumento da mesma na bacia de Santos pode ser observada na Figura 5.

Figura 5. Produção de Petróleo no Pós-sal - 2010 e 2018 (bbl/dia) Fonte: Elaboração própria utilizando dados da ANP/SIGEP Produção (2019)

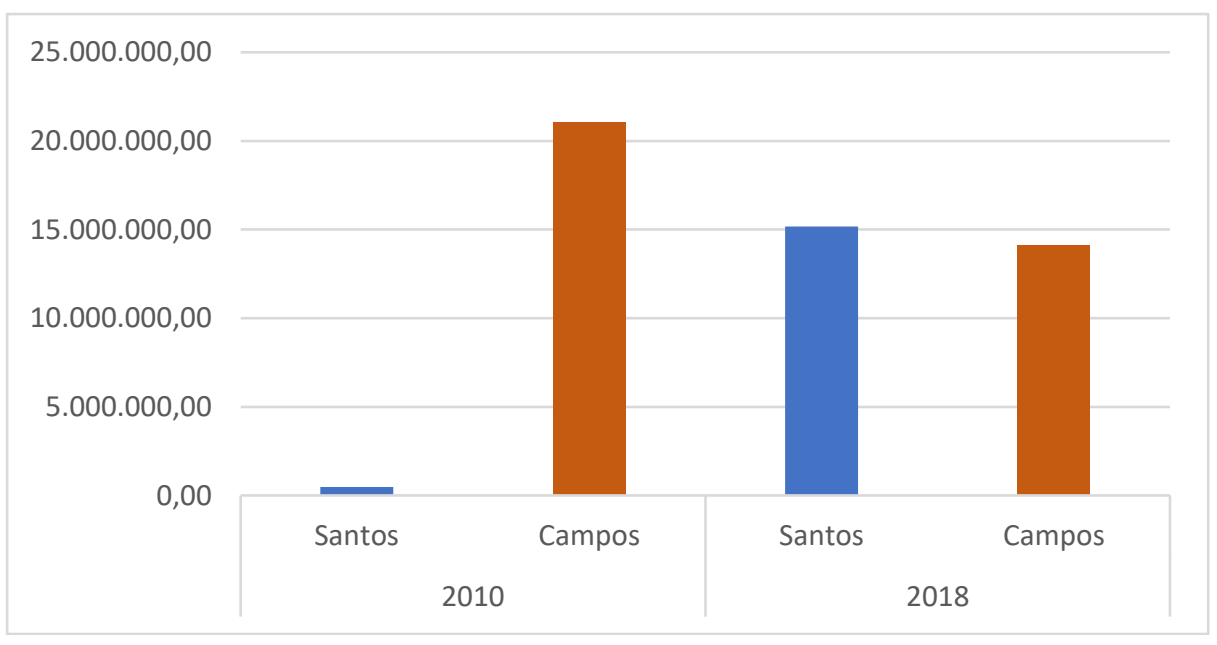


Existem, entretanto, tecnologias para gestão de poços maduros capazes de aumentar a vida útil aumentando assim o percentual recuperado - Recuperação de Óleo Melhorada (Enhanced Oil Recovery EOR) e Recuperação de Óleo Avançada (Improved Oil Recovery - IOR). ${ }^{14}$ Outras medidas também podem contribuir neste mesmo sentido, tais como a resolução da ANP que reduz até $5 \%$ a cobrança de royalties sobre a produção incremental em campos maduros (ROCKMANN, 2019).

No caso específico da indústria perolífera, por constituir atividade de capital intensivo, tecnologicamente sofisticada e, ainda, desejada e disputada internacionalmente, os benefícios dela advindos poderão ser altamente positivos. A rigor, mais do que o tamanho das reservas de óleo e gás propriamente ditas é a diversidade industrial de uma economia nacional, capaz de fornecer equipamentos e a prestação de serviços essenciais à indústria petrolífera, o fator mais importante para garantir os efeitos multiplicadores (Nordas, 2003).

A "diversidade industrial" referida anteriormente não se restringe ao local, nem sequer ao plano nacional, pois as empresas que operam nas etapas tecnologicamente mais sofisticadas do setor petrolífero (tais como as atividades de sísmica) são de âmbito internacional, o que remete a análise dos impactos dessa indústria ao âmbito nacional e até mesmo internacional, o que será sumariamente apresentado nas conclusões a seguir.

\section{CONCLUSÕES}

As transformações estruturais da geopolítica do petróleo tornam os prognósticos sobre a evolução do setor um terreno altamente movediço, embora sejam necessárias análises de cenários futuros. Contudo, o relatório global sobre as perspectivas do setor de energia da British Petroleum - BP comprova-se a importância do Brasil nesses cenários, pois afirma que, até 2040, a produção de petróleo brasileira vai avançar em um ritmo anual superior à dos Estados Unidos, e que o Brasil responderá por 23\% do aumento da produção mundial de petróleo entre 2017 e 2040 (SAMORA, 2019).

A projeção acima citada explica o grande interesse das petroleiras pelas licitações brasileiras, tendo em vista que as projeções de demanda do produto estariam asseguradas até 2050, o que justificaria a busca por novas jazidas em substituição àquelas que se esgotam.

No pré-sal brasileiro as jazidas guardam volumes extraordinariamente elevados que garantiriam ao país o arranque de forma a se beneficiar da procura de petróleo nos próximos anos. A análise de Papaterra e Dutra

\footnotetext{
14 Método de recuperação que envolve a alteração das propriedades do óleo ou da rocha, tendo como objetivo melhorar a recuperação dos hidrocarbonetos através do favorecimento da vazão do óleo ou do deslocamento dos fluidos no reservatório por meios físico, químico ou térmico.
} 
(2018) revela que a posição brasileira é única em razão de dispormos de uma matriz energética calcada na hidroeletricidade, na biomassa e, na qual o cravão tem presença residual, o que permitiria o pleno aproveitamento das descobertas, sem comprometer as metas acordadas em Paris para a redução de emissões.

Seria inadmissível que, após quase um século de busca incessante da Petrobras, o país entregue às petroleiras internacionais e a qualquer preço o petróleo do pré-sal ou o exporte não agregando valor algum, sem garantir os dividendos gerados por esses recursos à sociedade brasileira.

Tendo presente que os debates sobre o futuro do petróleo brasileiro estão ocorrendo em um período político em que as "questões de mercado" ficam acima dos interesses do país e que o tema não desperta a participação do passado, só resta ao analista ter presente que não é na escala menor (local) onde se estrutura a força motriz capaz de promover o verdadeiro desenvolvimento sustentável de uma nação.

\section{REFERÊNCIAS}

ALMEIDA, Edmar; RIBEIRO, Fernanda Almeida. Impactos da restruturação da Petrobras. In: PIQUET, Rosélia; PINTO JUNIOR, Helder Queiroz. (org.).4 Transformações em Curso na Indústria Petrolífera Brasileira. Rio de Janeiro: E-papers Serviços Editoriais Ltda. 2018, p.37-58.

CAETANO FILHO, Elísio. O papel da pesquisa nacional na exploração e explotação petrolífera da margem continental da Bacia de Campos. In: PIQUET, Rosélia. (Org.) Petróleo, Royalties e Região. Rio de Janeiro: Garamand, 2003.

CARVALHO, Renato Cerqueira de. Aeroporto internacional de Cabo Frio: globalização, redes e fluxos. Dissertação (Mestrado em Planejamento Regional e Gestão da Cidade) - Universidade Candido Mendes, Campos dos Goytacazes - RJ, 2014.

CRUZ, José Luís Vianna. Dinâmica socioeconômica e Territorial no Estado do Rio de Janeiro Contemporâneo. In: Gerschman, S. e Santos, A. Saúde e Políticas no Rio de Janeiro. Rio de Janeiro: Editora Fiocruz. 2016.

DE NEGRI, J. A. et al. Poder de compra da Petrobras: impactos econômicos nos seus fornecedores. Brasília: Ipea: Petrobras, 2011.

DOWBOR, Ladislau, Síntese de Indicadores Sociais 2018 do IBGE. In: DOWBOR, Ladislau. Jornal dos Economistas, maio de 2019.

EMPRESA DE PESQUISA ENERGÉTICA (EPE). Matriz Energética e Elétrica. Disponível em: <http://epe.gov.br/pt/abcdenergia/matrizenergetica-e-eletrica>. Acesso em: 12 ago. 2019.

INSTITUTO DE ESTUDOS PARA O DESENVOLVIMENTO INDUSTRIAL (IEDI). Carta IEDI, n. 935 de 05/07/2019. Disponível em: < https://iedi.org.br/cartas/carta_iedi_n_941.html>. Acesso em 12 de ago. 2019.

MORAES ZOUAIN, Deborah et. al. Análise do desenvolvimento de Arranjos Produtivos Locais (APLs): um estudo de caso do município de Paraty (RJ). Revista de Administração Pública - RAP, vol. 45, núm. 2, marzo-abril, 2011, pp. 517-539

NAZARETH, Paula Alexandra; ARAÚJO, Nina Quintanilha; OLIVEIRA, Henrique Diniz de. O Rio de Janeiro e as rendas petrolíferas: a crise e os desafios do pré-sal. In: PIQUET, Rosélia; PINTO JUNIOR, Helder Queiroz. (org.). Transformações em Curso na Indústria Petrolífera Brasileira. Rio de Janeiro: E-papers Serviços Editoriais Ltda. 2018. p.161-214.

NAZARETH, Paula Alexandra. Avaliação de impactos das rendas petrolíferas: uma comparação de municípios do RJ e SP. XXIV Congresso Internacional do CLAD sobre a Reforma do Estado e da Administração Pública. Buenos Aires: Argentina,12 a 15 de novembro de 2019.

PASTORE, José. As mudanças no mundo do trabalho: leituras de sociologia do trabalho. São Paulo: MEC, SEB, 2000.

PAPATERRA, Guilherme; DUTRA, Luís. Ativos encalhados e o petróleo do pré-sal. Valor Econômico. 17 de dezembro de 2018.

PEREIRA, Lia Valls. As exportações fluminenses: a maldição dos recursos naturais? In: PINHEIRO, Armando; VELOSO, Fernando. Rio de Janeiro: um estado em transição. Rio de Janeiro: Editora FGV, 2012.

PETROBRAS S. A. Marco Regulatório. Disponível em: <http://novosited.petrobras.com.br/pt/nossas-atividades/areas-deatuacao/exploracao-e-producao-de-petroleo-e-gas/marco-regulatorio/> Acesso em 06 ago. 2019. 
RAMALHO, André. Petrobras concentra esforços no pré-sal. Valor Econômico. 11 de março de 2019.

ROCKMANN, Roberto. Primeiro escalão. Valor Econômico. 28 de janeiro de 2019.

SAMORA, Roberto. Produção de petróleo no Brasil crescerá mais rápido que a dos EUA até 2040, diz BP. Reuters. Notícias de Negócios, 14 de fevereiro de 2019. Disponível em: <https://br.reuters.com/article/businessNews/idBRKCN1Q32XT-OBRBS>. Acesso em 12 ago. 2019. 